Article

\title{
Congestion Evaluation of Pedestrians in Metro Stations Based on Normal-Cloud Theory
}

\author{
Jibiao Zhou ${ }^{1,2}{ }^{-}$, Yao $\mathrm{Wu}^{3, *}$, Xinhua Mao ${ }^{4,5, *}$, Shun Guo ${ }^{6}$ and Minjie Zhang ${ }^{1}$ \\ 1 School of Civil and Transportation Engineering, Ningbo University of Technology, Fenghua Rd. \#201, \\ Ningbo 315211, China \\ 2 College of Transportation Engineering, Tongji University, Caoan Rd. \#4800, Shanghai 201804, China \\ 3 Jiangsu Key Laboratory of Urban ITS, Jiangsu Province Collaborative Innovation Center of Modern Urban \\ Traffic Technologies, School of Transportation, Southeast University, Si Pai Lou \#2, Nanjing 210096, China \\ 4 School of Economics and Management, Chang' an University, Xi'an 710064, China \\ 5 Department of Civil and Environmental Engineering, University of Waterloo, Waterloo, \\ ON N2L 3G1, Canada \\ 6 Faculty of Maritime and Transportation, Ningbo University, Fenghua Rd. \#818, Ningbo 315211, China \\ * Correspondence: wuyaomaster@126.com (Y.W.); mxinhua@uwaterloo.ca (X.M.)
}

Received: 26 July 2019; Accepted: 28 August 2019; Published: 3 September 2019

Featured Application: This study may promote the risk management and control level under high-density pedestrian flow, which is significant for the expansion of the scope and field of early warning applications.

\begin{abstract}
This study aims at evaluating the congestion level of pedestrians in metro stations. Twelve hours ( $4 \mathrm{~h} \times$ three facilities) of video data were collected in the channel, stairway, and platform in a metro station in the city of Ningbo, China. The indicator of GPC (grade of pedestrian crowd) was proposed to quantify the congestion level of pedestrians. Four levels of congestion (level I, level II, level III, and level IV) were determined based on the GPC. A normal-cloud (NC) model was proposed and calibrated for the evaluation of three facilities including channel, stairway, and platform. The evaluation results showed that the GPC of L1-L2 and L2-L1 in channel are level II and level I, respectively. The GPC of upward and downward of stairway are level III and level I. The GPC of platform is level IV. Crowd management countermeasures were proposed for the management of pedestrians in metro station.
\end{abstract}

Keywords: congestion level of pedestrians; evaluation; normal-cloud theory; metro station

\section{Introduction}

Metro stations are important infrastructure in the urban rail transit system because they are the distribution hubs for transferring passengers on/off board [1]. The contradiction in demand and capacity of the rail transit facility has become increasingly prominent with the rapid growth of passenger flow, highly concentrated in space and time. In China, by 2018, the total rail transit passenger reached 21.07 billion, which was 2.59 billion more than that in 2017, a 14\% increase from last year [2]. The total RPK (revenue passenger kilometers) of rail transit is 176.08 billion-person kilometers, the average passenger intensity in 2018 was 8000 person/(km.day) [2]. The rail transit corporations, such as Beijing, Shanghai, and Guangzhou, have put forward restrictive measures on the rapid expansion of the passenger flow [3]. Traditionally, the metro stations are featured with closed space, complex facilities, short-term clustering, and uneven distribution of passenger flow. As such, controlling the large passenger flow has become a great challenge. A better understanding of the pedestrian congestion level would be beneficial to pedestrian flow management and control in metro stations. 
Most stations in metro networks are irreplaceable due to daily operations. If any of them were disrupted, it would impact not only the individual metro line but also the whole urban rail transit networks [4]. For example, recent years have evidenced several natural or man-made disasters that have prompted the evacuation of passengers in major metro/train/bus stations, resulting in fatalities and injuries [5,6]. Moreover, metro networks are not incident free since heavy crowds may cause discomfort to passengers and even accidents [7]. Kyriakidis et al. [8] divided the incidents into six categories, including passengers, technical failures, human performance, fires, malicious or illegal action, and management action, which represent the accident precursors as well. Yang et al. [4] indicated that common incidents in metro networks included collapses, leaks, fires, and terrorist attacks. Therefore, assessing the pedestrian congestion level was critical for the urban rail transit systems. It is beneficial not only to understand passenger satisfaction [9-11] but also to assess the causes and develop corresponding strategies to manage or relieve congestion and improve safety [12-17].

The primary objective of this paper was to evaluate the passenger congestion level in metro stations. An indicator, the grade of pedestrian crowd, short for GPC, was defined to quantify the passenger congestion level from I to IV, ranges from 0 to 10, the interval value for each level is 2.5, which corresponds to excellent, good, ok, and bad. The status description of Level I to IV is completely unimpeded, relatively unimpeded, slightly impeded, and heavily impeded, correspondingly. The higher the value of the GPC, the more serious the pedestrian flow crowd is. Three facilities including the channel, stairway, and platform, were consideration for the evaluation. A normal-cloud (NC) model was used for the evaluation. The analysis was demonstrated using a case study from the city of Ningbo, Zhejiang province, China.

\section{Literature Review}

The transformation of the urban rail transit system from a phase of large-scale construction to a phase of meticulous management and operation has led to the problem of station overcrowding for the department of rail transportation management $[18-20]$. Most of the previous studies $[15,17,18]$ on passenger crowding at urban rail transit systems mainly focus on the impacts of passenger crowding, measures to track passenger crowding, and benefits of monitoring passenger crowding.

\subsection{Impacts of Passenger Crowding}

Previous studies have shown that passenger crowding is a subjective feeling reflected by individuals in a space with an oversized crowd [21-23]. It is caused by multiple factors, such as individual characteristics, space environment, and passenger density [21]. Crowd assessment has become a growing concern because the huge demand for passenger traffic has far exceeded the station's capacity. Jiang et al. [22] established a grading criterion for crowding based on the standing density (i.e., the number of standing passengers per square meter). The study found that changes in crowding significantly affected the passengers' choice for a bus or a rail transit. Basu et al. [23] evaluated the attributes that affected the attractiveness of the intercity rail transit in Mumbai, India.

Moreover, the short-term passenger flow forecasting technology can also be applied for assessing passenger crowding in the urban rail transit station due to the demand for risk management of the rail transit network that has been developed from the post analysis stage to the advance prevention stage. Tirachini et al. [24] analyzed the impact of passenger congestion on demand for public transport systems. The results showed that congestion affected the results of demand forecasting. The demand was overvalued or underestimated on neglecting the congestion costs. Yang et al. [25] established a real-time forecasting model for the large-scale passenger traffic based on Gray-Markov. The passenger flow was validated and optimized using the historical OD (Origin-Destination) data from Beijing rail transit, and the predicted results were close to the real passenger flow. 


\subsection{Measures to Track Passenger Crowding}

Previous studies divided the crowding status into five or six levels to characterize the degree of crowding in the station, with considering the LOS (Level of Service) and the passenger density of the facilities such as channel, stairway, and platform [26-28]. For instance, a related study by Lam et al. [26] set up the crowding assessment of the light rail transit by dividing the LOS of the station platform into five categories. Their results provided a reference for the safety assessment of the facilities. Cao et al. [27] classified the LOS criteria of the rail transit channels in Beijing. It was found that the criteria values were lower than that in the HCM 2010. Similarly, Chen et al. [28] assessed right-turning vehicle-pedestrian conflicts at intersections, their results provided that the frequency and severity of conflict can be represented by SSMs (surrogate safety measures).

To our knowledge, there are few studies focusing on the grading criteria of the crowding degree in the metro station. There are no uniform criteria for grading of the crowding levels, while it was mainly referred to as the passenger standing density. In some countries [29-32], such as Australia, The Netherlands, Chile, USA, etc., the standards for the passenger standing density were divided into two categories: the comfortable criterion with a standing density of three passengers per square meter and the crowding criterion with a standing density of six passengers per square meter. For example, in the US, the Transit Capacity and Quality of Service Manual (TCQSM) [33] provides guidance and reference for measuring passenger crowding. It contains official definitions of station capacity, and pedestrian levels of service (LOS) [27]. In China, there have been three different criteria for the passenger standing density $[20,21,34-36]$.

The literature review indicated that previous studies focused on passenger crowding were undertaken at a microcosmic level. Most crowding identification studies rely on ridership data but do not explain much information about the uncertainty and fuzziness nature of the passenger distribution in the metro station. Furthermore, little is known about the grade of crowding that characterizes the congestion degree of the channel, stairway, and platform facilities in the urban rail transit system. Hence, this study developed a NC model to examine simultaneously the passenger crowding status associated with the forward normal cloud generator and the grade of crowding. A forward normal cloud generator was used to determine the digital eigenvalues of the template cloud and the candidate cloud as well as the GPC was calculated according to the principle of the maximum membership degree.

\section{Data}

\subsection{Data Collection}

Data was collected in a metro station in city of Ningbo, China. Ningbo is one of the biggest cities along the east coast of China, which is also one of the richest cities in China [37]. As of 2018, Ningbo has operated two metro lines (i.e., Line 1 and Line 2). Line 1 has 29 stations with a line length of $46.15 \mathrm{~km}$; Line 2 has 22 stations with a line length of $28.35 \mathrm{~km}$; and a transfer station (i.e., Gulou station). Line 1 has an interval of $4 \mathrm{~min}$ and $40 \mathrm{~s}$ during the morning rush hour, $5 \mathrm{~min}$ and $7 \mathrm{~s}$ during the evening peak hours, and $6 \mathrm{~min}$ and $30 \mathrm{~s}$ during the peak period. Line 2 has an interval of $4 \mathrm{~min}$ and $56 \mathrm{~s}$ during the morning rush hour, $5 \mathrm{~min}$ and $22 \mathrm{~s}$ during the peak hours, and $6 \mathrm{~min}$ and $30 \mathrm{~s}$ during the peak period. According to the annual report of China urban mass transit [2], a daily average of 341,000 passengers travel over the metro by Line 1 and Line 2 in Ningbo, which covers the highest hourly passenger flow is 12,000 passengers on Line 1, and 8100 passengers on Line 2. Figure 1 shows the transition station between the two lines. The Gulou station is located at Zhongshan Road and Jiefang Road, where the two metro lines run through in the form of a cross in the downtown area. The station has three floors underground and is in an island type. The Line 1 platform is located on the third floor (i.e., 3F), and the Line 2 platform is located on the second floor (i.e., 2F). The platforms of the two metro lines are connected with several stairways and an "L"-shaped channel (see Figure 2).

The Gulou station was chosen as the data collection site due to the large passenger volume. During data collection, three cameras were designed to videotape the passenger flow data at three spots: 
a channel, a stairway, and a platform. The number of weekdays of video recording are all weekdays of April 2018, from April 2 to 30, and the total number is 21 days. The basic information of the data collection spots in the three facilities (i.e., channel, stairway, and platform) is shown in Figure 2.

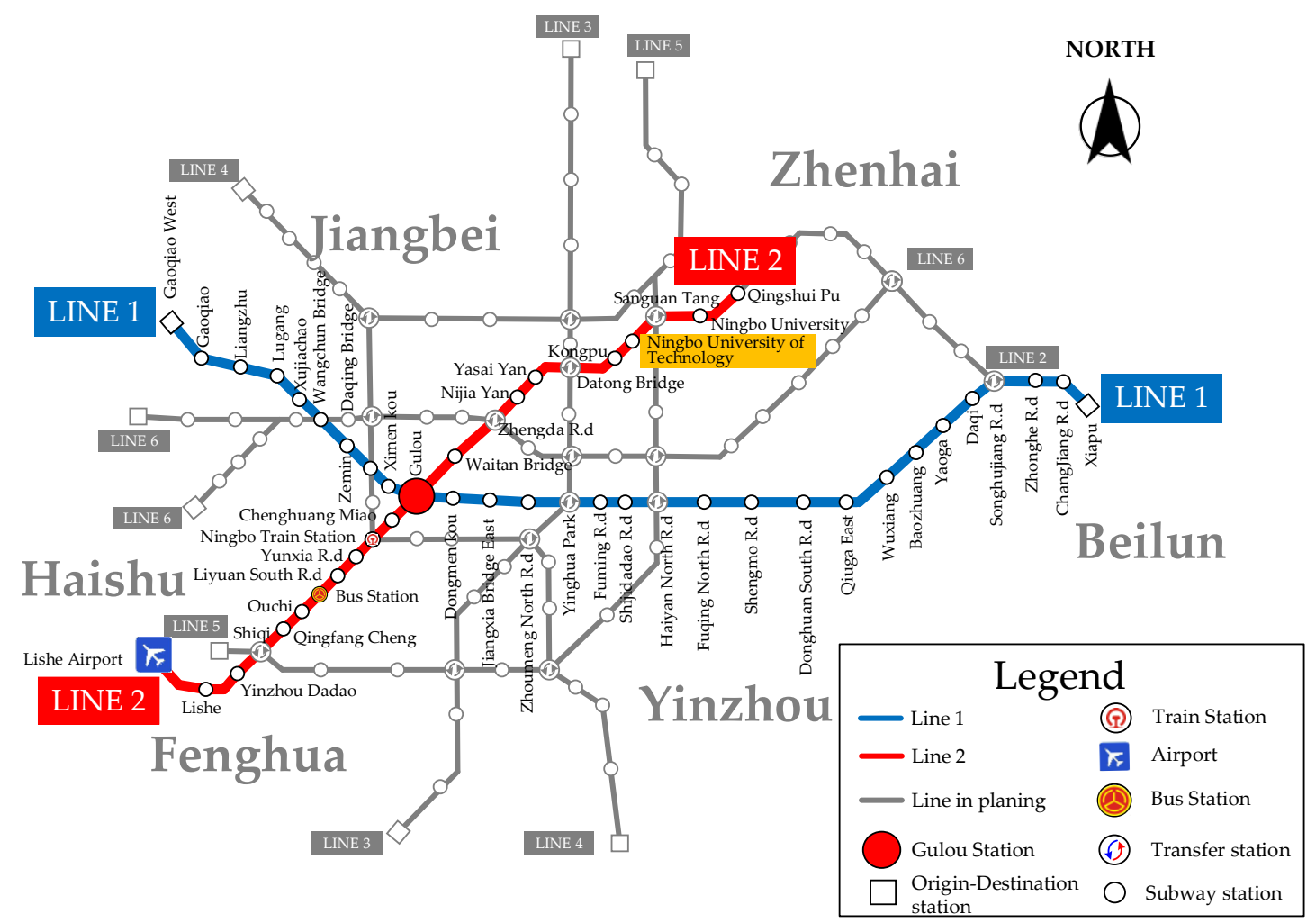

Figure 1. The location of Gulou station.

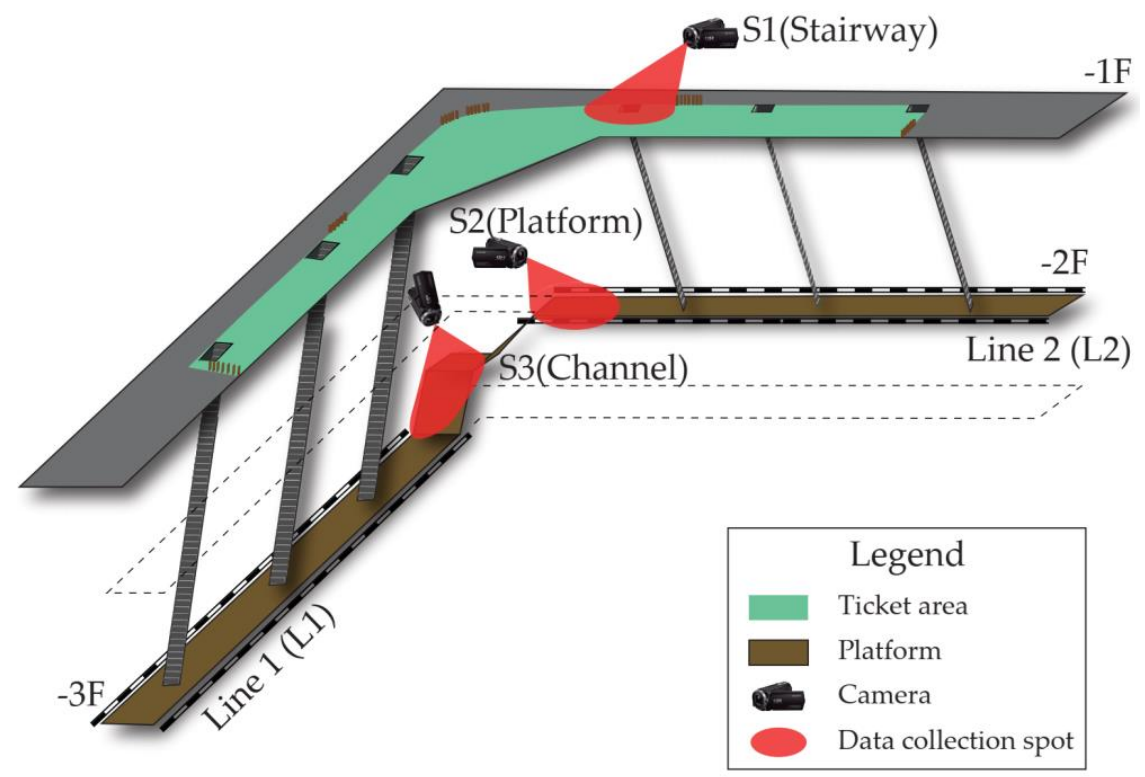

Figure 2. The data collection spots.

\subsection{Data Results}

The video data at the channel, stairway, and platform were manually checked and screened. Four statistic metrics, the average value of all weekdays, which are used as evaluation indicators in 
the following analysis, for each facility were calculated, which were (a) passenger-occupied space $\left(\mathrm{m}^{2} /\right.$ ped), coded as P1; (b) average walking speed (m/min), coded as P2; (c) passenger flow in unit width (ped/(min.m)), coded as P3; and (d) average passenger gap (m), coded as P4.

Figure 3 shows the changes in the four metrics P1-P4 for the three facilities during the evening peak hour (i.e., 5:00 P.M. to 7:00 P.M.). The values of four metrics (P1-P4) are the average values. As the channel and the stairway had two directions, each direction was indicated by either a positive or a negative value on the $y$-axis as the legend specified, while the magnitudes remained the same.

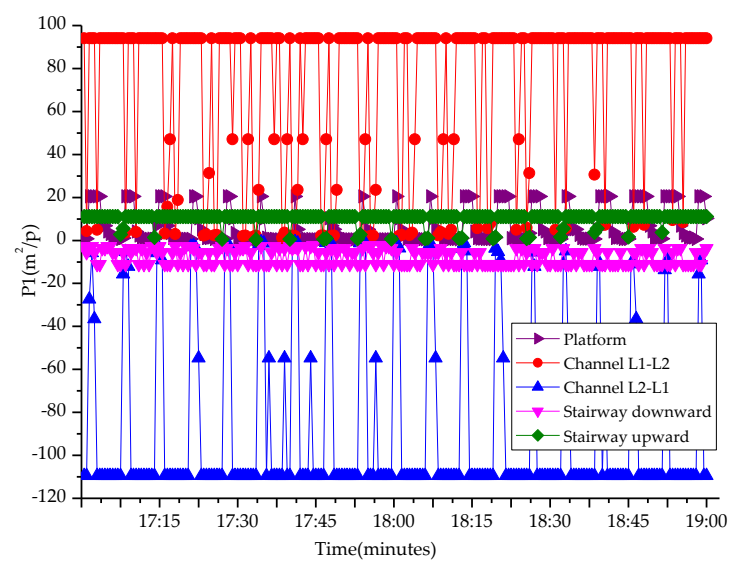

(a)



(c)

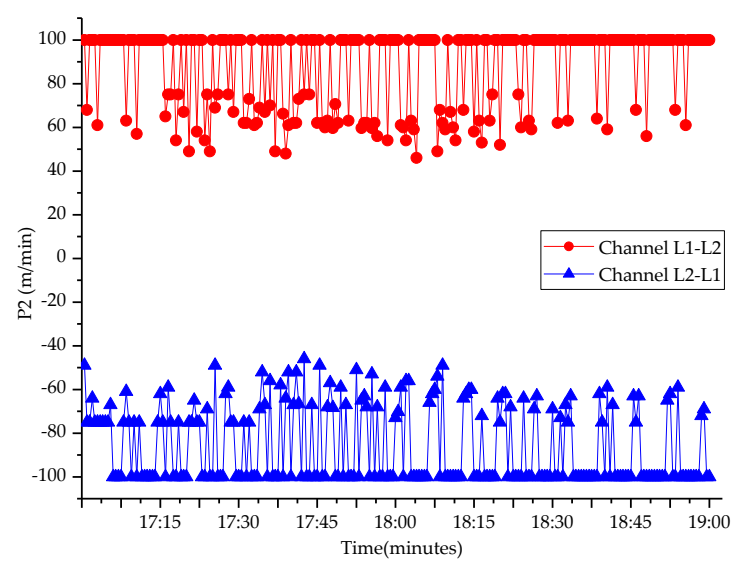

(b)

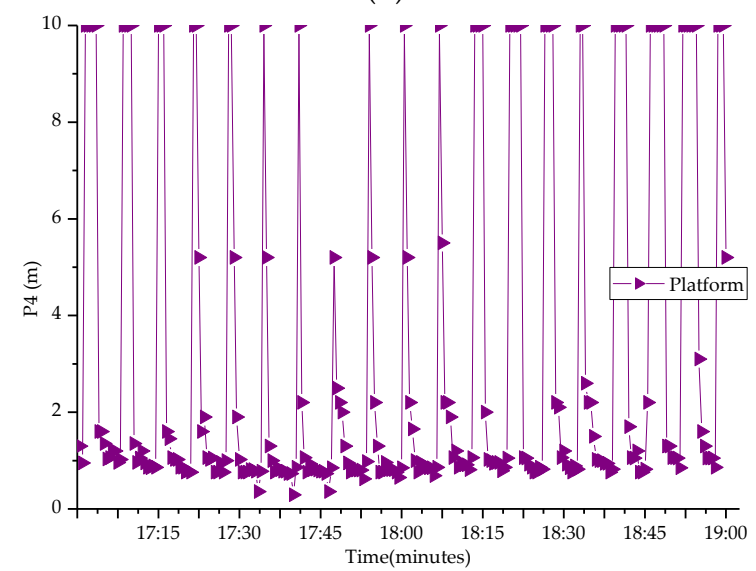

(d)

Figure 3. Results of the four metrics for the facilities of Gulou station. (a) P1: pedestrian occupied space $\left(\mathrm{m}^{2} /\right.$ ped). (b) P2: average walking speed $(\mathrm{m} / \mathrm{min})$. (c) P3: passenger flow per unit width (ped/(min.m)). (d) P4: average pedestrian gap $(\mathrm{m})$.

\section{Methodology}

\subsection{Problem Statements}

At present, no uniform criteria exist on the grading thresholds of the GPC in metro stations. A LOS criterion in six levels from A to $\mathrm{F}$ was used in previous studies $[20,21,23-25,36,38,39]$ where Level A referred to the free flow and Level $\mathrm{F}$ to the congestion flow. The GPC for each facility at the study site was determined using this criterion (see Table 1).

Since three facilities were considered in the evaluation of grade of crowd, and each facility uses different evaluation indictors, the following problems are raised.

1. Uncertainty: As at least two indicators were used for each facility, the congestion assessment results were different when applying the criterion in Table 1 . Taking the crowding assessment in the channel as an example, the LOS was $C$ when using $\mathrm{P} 1=2.29 \mathrm{~m}^{2} /$ ped. When using 
$\mathrm{P} 2=63.50 \mathrm{~m} / \mathrm{min}$, the LOS was E. When using P3 $=25.63 \mathrm{ped} /(\mathrm{min} \cdot \mathrm{m})$, the LOS was B. Thus, uncertainty was seen in the assessment as a same indictor resulting in different LOS results.

2. Ambiguity: No agreements existed on the criteria of the LOS assessment. Although the TCQSM, 2nd Edition [33] provided the division of the index for each facility, it was mainly based on the situation in the United States. Thus, it was weak for the practice guidance of China's rail transit. An accurate and reasonable threshold division as to when to determine the grade of crowd for a certain passenger flow is still lacking. Thus, ambiguity was seen in the congestion assessment.

Table 1. The crowding status for the facilities at Gulou Station.

\begin{tabular}{|c|c|c|c|c|c|c|c|}
\hline \multirow{2}{*}{ LOS } & \multicolumn{3}{|c|}{ Channel } & \multicolumn{2}{|c|}{ Stairway } & \multicolumn{2}{|c|}{ Platform } \\
\hline & P1 & P2 & P3 & P1 & P3 & P1 & P4 \\
\hline A & $\geq 3.3$ & $>79$ & $0-23$ & $\geq 1.9$ & $\leq 16$ & $\geq 1.2$ & $\geq 1.2$ \\
\hline B & $2.3-3.3$ & $76-79$ & $23-33$ & $1.4-1.9$ & $16-23$ & $0.9-1.2$ & $1.1-1.2$ \\
\hline C & $1.4-2.3$ & $73-76$ & $33-49$ & $0.9-1.4$ & $23-33$ & $0.7-0.9$ & $0.9-1.1$ \\
\hline D & $0.9-1.4$ & $69-73$ & $49-66$ & $0.7-0.9$ & $33-43$ & $0.3-0.7$ & $0.6-0.9$ \\
\hline E & $0.5-0.9$ & $46-69$ & $66-82$ & $0.4-0.7$ & $43-56$ & $0.2-0.3$ & 0.6 \\
\hline $\mathrm{F}$ & $<0.5$ & $<46$ & vary & $<0.4$ & vary & $\leq 0.2$ & vary \\
\hline
\end{tabular}

Notes: P1 is Pedestrian-occupied space $\left(\mathrm{m}^{2} /\right.$ ped); P2 is average walking speed $(\mathrm{m} / \mathrm{min}) ; \mathrm{P} 3$ is passenger flow in unit width $(\mathrm{ped} /(\mathrm{min} \cdot \mathrm{m})) ; \mathrm{P} 4$ is average pedestrian gap $(\mathrm{m})$.

\subsection{Model Framework}

The conceptual model framework of this study, consisting of three processes: (a) input stage, (b) processing stage, and (c) outcome stage, was proposed to assess the GPC in metro stations using the NC model theory (see Figure 4).

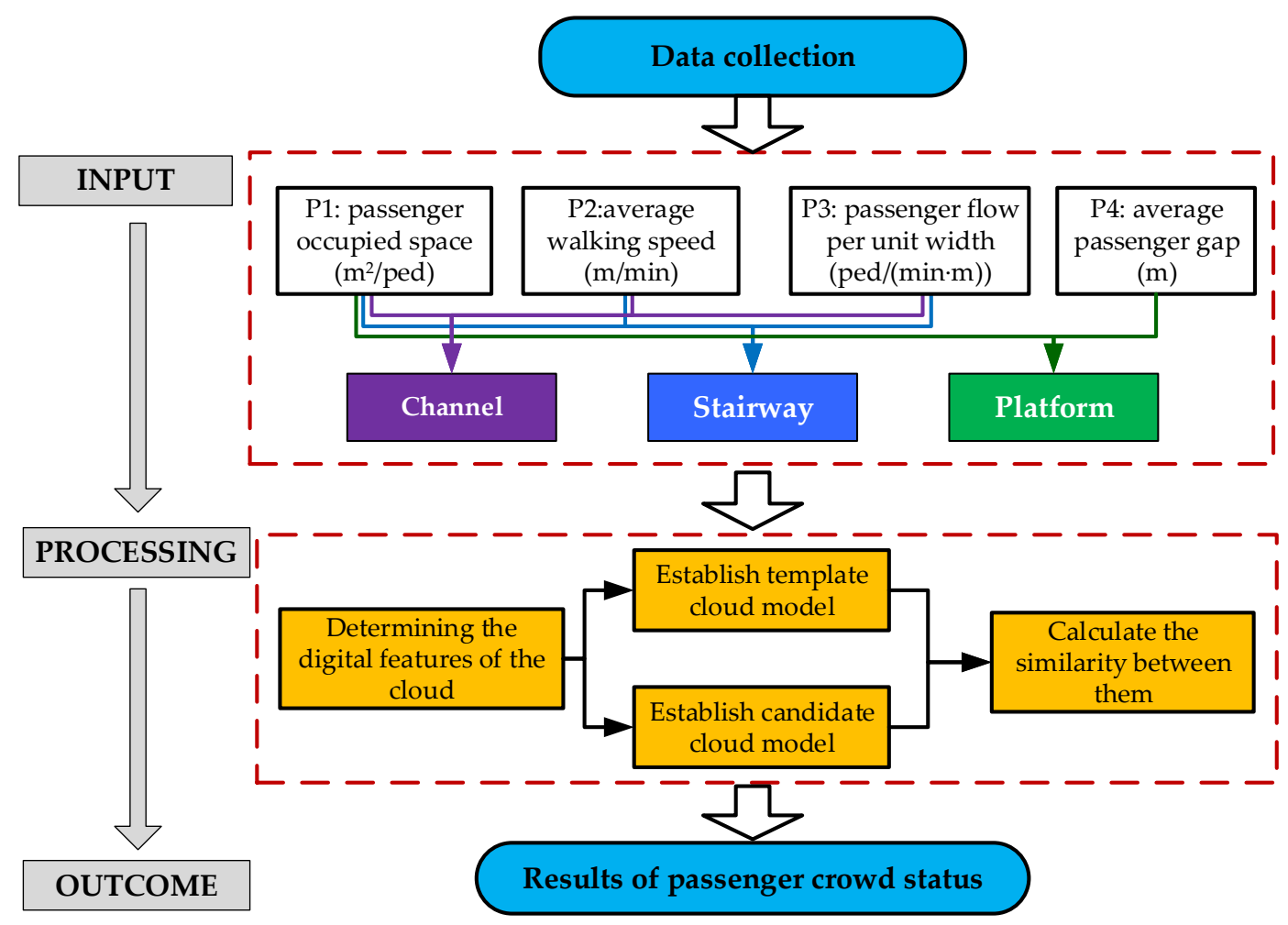

Figure 4. Conceptual model framework procedure.

The input of model included three facility measures: channel, stairway, and platform. The channel indicators included passenger-occupied space (P1), average walking speed (P2), and passenger flow in unit width (P3). Similarly, the stairway indicators included passenger-occupied space (P1), average 
walking speed (P2), and passenger flow in unit width (P3). Finally, the platform indicators included passenger-occupied space (P1) and average passenger gap (P4). In the processing procedure, the $\mathrm{CN}$ modeling technique was used to assess the GPC in the metro stations. The result of the conceptual model framework was the GPC criterion related to the pedestrian congestion level.

\subsection{NC Model}

The NC (normal-cloud) model was proposed by Li et al. [40], which included qualitative and quantitative mapping mainly through the combination of the fuzzy and random sets of an object to study the universal law among uncertainties. The NC model currently provides the best solutions to many problems in effectiveness evaluation, decision making, risk assessment, and condition assessment of bridges [41,42]. In this study, the NC model was used to evaluation the GPC in metro stations. The steps to construct a cloud model were as follows.

1. Cloud model: Let $U$ be a quantitative domain and let $C$ be a qualitative concept on $U$. If a certain value $x \in U$, then $x$ is a random implementation of $C$. The determinacy of $x$ to $C$ is a random number with a stable tendency $\mu(x): U \rightarrow[0,1], \forall x \in U, x \rightarrow \mu(x)$. Then, the distribution of $x$ on the domain $U$ is called a cloud, and each $\mathrm{x}$ is described as a cloud droplet. Three parameters, the expectation $E x$, the entropy $E n$, and the super-entropy He, are used to characterize the normal-cloud model, as shown in Figure 5.

2. NC generator: If the definition of $x$ in the cloud satisfies $\mathrm{x} \sim N\left(E x, E n^{\prime}\right)$ and $E n^{\prime} \sim N\left(E n, H e^{2}\right)$, the determinacy of $x$ to $C$ satisfies the following:

$$
\mu(x)=\operatorname{Exp} \frac{-(x-E x)^{2}}{2\left(E n^{\prime}\right)^{2}} .
$$

The NC model is widely used in solving probabilistic and ambiguous problems, which combines the normal distribution function with the bell-shaped membership function. All the cloud models used in this study referred to the NC model. By definition, the quantitative data obtained from cloud digital eigenvalues were forward NC generators, while those obtained from the quantitative data were backward NC generators. In this study, the forward NC generator was used to solve the NC model, see Figure 6.

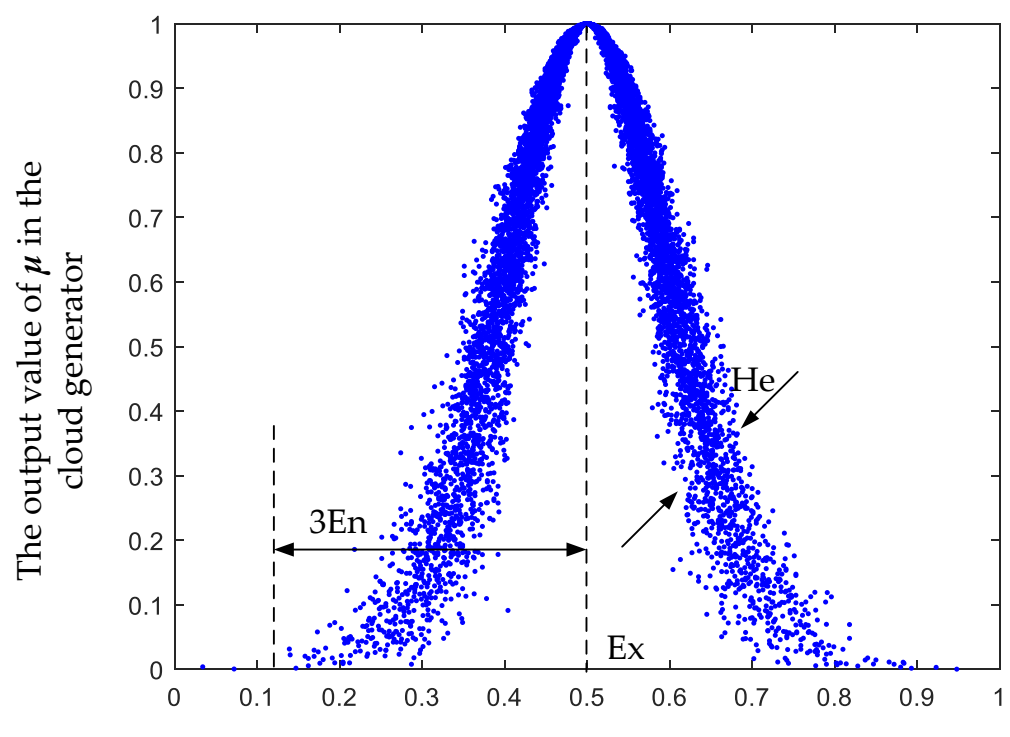

The value of $x^{*}$ after $x$ standardized

Figure 5. Basic normal-cloud (NC) model. 


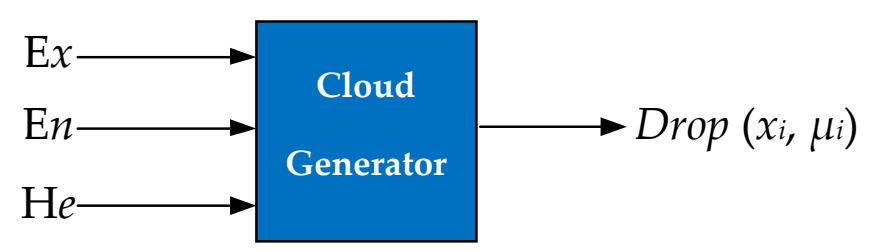

Figure 6. Forward NC generator.

3. Cloud synthesis: The synthesis of clouds was to combine the clouds of the same nature with a parent cloud. The parent cloud $C(E x, E n, H e)$ was synthesized using $n$ child clouds $C n\left(E x_{n}, E n_{n}\right.$, $\left.H e_{n}\right)$, expressed as follows:

$$
\begin{aligned}
& C=C_{1} \circ C_{2} \circ C_{3} \circ \cdots \circ C_{n} \text {, } \\
& \left\{\begin{array}{c}
E x=\frac{\sum_{i=1}^{n} E x_{i} \times E n_{i} \times w_{i}}{\sum_{i=1}^{n} E n_{i} \times w_{i}} \\
E n=\sum_{i=1}^{n} E n_{i} \times w_{i}, \\
H e=\frac{\sum_{i=1}^{n} H e_{i} \times E n_{i} \times w_{i}}{\sum_{i=1}^{n} E n_{i} \times w_{i}}
\end{array}\right.
\end{aligned}
$$

where "o" refers to the process of cloud synthesis and $w_{i}$ to the weight of the $i$-th child cloud.

4. Model of GPC: The process of the model followed five steps:

Step 1: Determining the digital features of the cloud

Let $X=\left(x_{1}, x_{2}, \ldots, x_{j}, \ldots, x_{n-1}\right)$ be the threshold vector of an index in which $x_{j}$ denotes the threshold of the index at $j$-th GPC. As the synthetic clouds were conducted in the same domain, the index needed to be standardized before calculating the digital features. Using the bigger-is-better and the smaller-is-better rules, the standardizations were as shown in Equations (4) and (5), respectively.

Bigger is better,

$$
x_{j}^{*}=\frac{x_{j}-\min \left\{x_{j}\right\}}{\max \left\{x_{j}\right\}-\min \left\{x_{j}\right\}} \quad(j=1,2, \ldots, n-1) .
$$

Smaller is better,

$$
x_{j}^{*}=\frac{\max \left\{x_{j}\right\}-x_{j}}{\max \left\{x_{j}\right\}-\min \left\{x_{j}\right\}} \quad(j=1,2, \ldots, n-1),
$$

where $x_{j}^{*}$ is the standardized value of $x_{j}$, and $\max \left\{x_{j}\right\}$ and min $\left\{x_{j}\right\}$ are the maximum and minimum values for the threshold $j$, respectively.

The GPC $j(j=1,2, \ldots, n-1)$ is indicated by NCs in the semi-rising and semi-descending states, leading to the three digital features in Equation (6). Then, the other grades are indicated by NCs in full states, and their corresponding digital features are calculated as follows:

$$
\begin{aligned}
& E x_{x 1}=x_{1}^{*}, E n_{x 1}=E n_{x 2} \\
& E x_{x n}=x_{n-1}^{*}, E n_{x n}=E n_{x n-1}{ }^{\prime} \\
& \left\{\begin{array}{l}
E x_{x j}=\left(x_{j-1}^{*}+x_{j}^{*}\right) / 2 \\
E n_{x j}=\left(x_{j-1}^{*}-x_{j}^{*}\right) / 6 \\
H e=0.01(j=2, \ldots, n-1)
\end{array} .\right.
\end{aligned}
$$


Step 2: Establishing the template cloud model

Synthesizing all the indexes of child clouds under the GPC criterion in $n$ grade results in the parent cloud, which is called the template cloud or standardized cloud and uses a standard cloud map to assess the crowd state in the metro station. For example, a certain facility has three indexes, and each of their child clouds is denoted as $R_{j}, S_{j}$, and $T_{j}$. Thus, the parent cloud $U_{j}$ was synthesized as $U_{j}=R_{j} \circ S_{j} \circ T_{j}(j=1,2, \ldots, n)$, and can be referred from Equation (3).

Step 3: Establishing the candidate cloud model

1. Establish a forward cloud generator $\mathrm{CG}_{X j}$, according to the digital features of the GPC index in the rail station.

2. Standardize the actual values $x$ collected by the index and marked as $x^{*}$. Let the standardization results of index in $x \leq \min \left\{x_{j}\right\}$ be 0 and index in $x \geq \min \left\{x_{j}\right\}$ be 1 .

3. Input the standardized values $x^{*}$ into the forward NC generators, as shown in Figure 7, for the operating principle of the forward NC generator.

4. Output of the cloud generator, $\mu_{X j}(j=1,2, \ldots, n)$, represents the degree of $x$ belonging to $X j$. The fuzziness and randomness nature of the NC model indicates that, instead of a determined number, $\mu_{X j}$ is a random number with a stable tendency. After normalizing all $\mu_{X j}$, Equation (8) shows the weights $\omega_{X j}$ for each $X_{j}$ :

$$
\omega_{X j}=\frac{\mu_{X j}}{\sum_{j=1}^{n} \mu_{X j}} .
$$

Using the digital features of the child clouds calculated from Equation (3), cloud $X x\left(E x_{X}, E n_{X}\right.$, $\left.H e_{X}\right)$ is obtained where $x$ is the input.

5. Calculate the three digital features of the candidate clouds for other indexes in the rail transit station using Steps (1) to (3).

6. Synthesize the candidate cloud $U^{\prime}$ so that $U^{\prime}=R r \circ S s \circ T t=(E x, E n, H e)$, as referred to in Equation (10), where $R r, S s$, and $T t$ are the clouds calculated by each index.

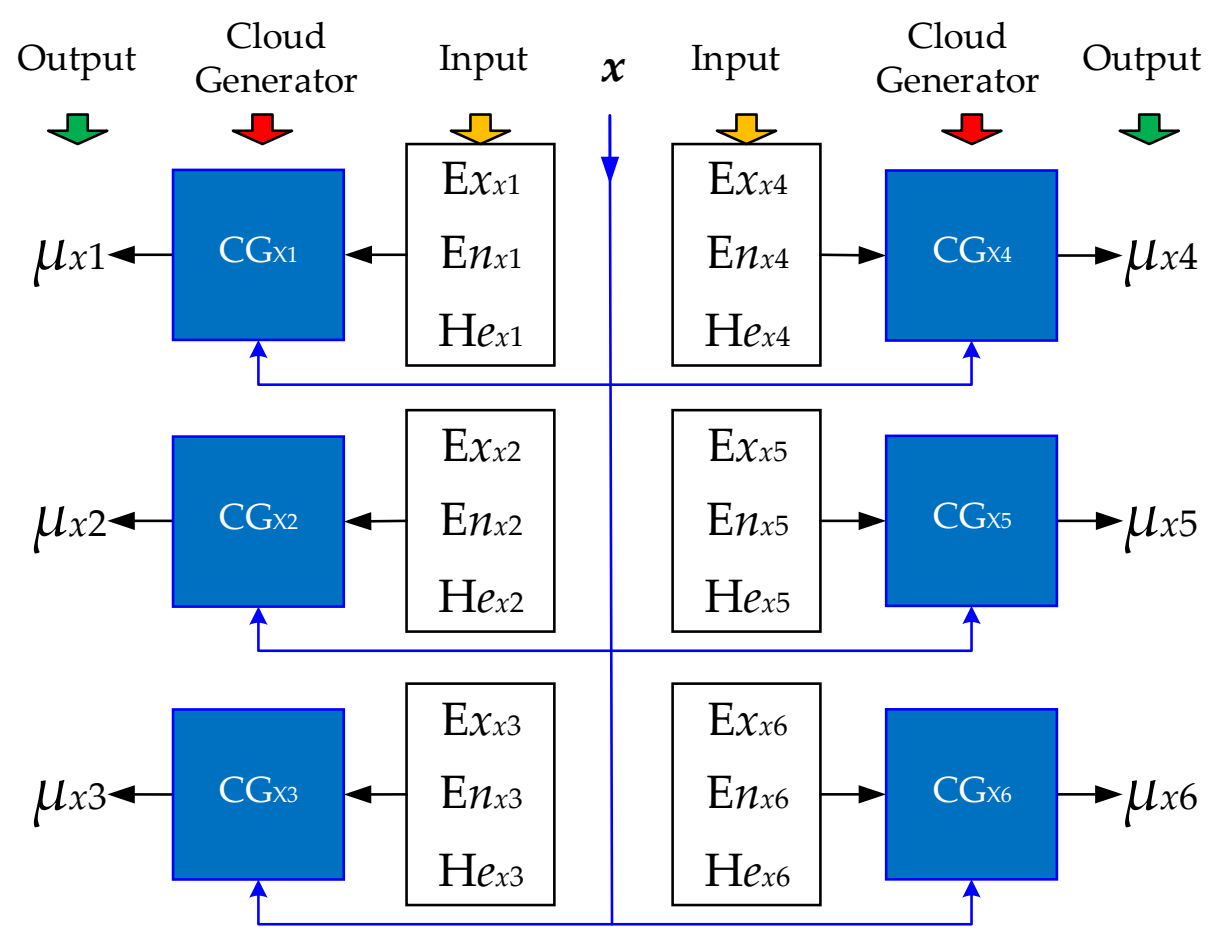

Figure 7. Operating principle of the forward NC generator. 
Step 4: Calculating the similarity between the assessing and template clouds

The similarities between the candidate cloud $U^{\prime}$ and each template cloud $U j$ should be calculated first to assess the passenger crowd statuses. Assume two clouds $U^{\prime}$ and $U ; U^{\prime}$ generates cloud members $x i(i=1,2,3, \ldots, N)$, which belong to $U$ with a degree of $\beta i$. Thus, cloud similarity between $U^{\prime}$ and $U$ is defined as follows:

$$
\delta=\frac{1}{N} \sum_{i=1}^{N} \beta_{i} .
$$

The detailed calculation steps for the cloud similarity were as follows:

1. Generate normal random numbers Eni' in the candidate cloud, with the expected value $E n$ and the variance $H e^{2}$, that is, $E n i^{\prime}=N\left(E n, H e_{2}\right)$.

2. Generate normal random numbers $x i$ in the candidate cloud, with the expected value $E x$ and the variance $E n_{i}{ }^{2}$, that is, $x i=N\left(E x, E n_{i}{ }^{2}\right)$.

3. Generate normal random numbers $E n j$ in the template cloud, with the expected value $E n_{j}$ and the variance $H e_{j}{ }^{2}$, that is, $E n_{j}{ }^{\prime}=N\left(E n j, H e j^{2}\right)$.

4. Calculate the degree of the membership $\left(\beta_{i j}\right)$ for the $j$-th GPC, that is, $\beta_{i j}=\exp \left[-\left(x_{i}-E x_{j}\right)^{2} / 2 E n j^{\prime 2}\right]$.

5. $\quad$ Repeat Steps (1) to (4) until $n$ members of clouds are generated.

6. Calculate the cloud similarity $\delta_{j}$ between the candidate cloud $U^{\prime}$ and each template cloud $U_{j}$, as follows:

$$
\delta_{j}=\frac{1}{N} \sum_{i=1}^{N} \beta_{i j} .
$$

7. Normalize $\delta_{j}$ using Equation (9). The possible GPC that the candidate cloud belongs to is indicated by $\lambda_{j}$ and calculated as follows:

$$
\lambda_{j}=\delta_{j} / \sum_{j=1}^{n} \delta_{j} .
$$

It is easy to find out that the more the member clouds $x i$ in $U^{\prime}$ fall into the template cloud $U_{j}$, the bigger the cloud similarity $\delta_{j}$. This also means the greater the possibility $\left(\lambda_{j}\right)$ that the candidate cloud (i.e., state) is closer to the $j$-th GPC.

Step 5: Calculating the GPC

Finally, $\varepsilon$ was defined based on the result of the similarity assessment between the candidate and template clouds. The calculation is shown as follows:

$$
\varepsilon=\left[\left(\sum_{j=1}^{n} \lambda_{j} \times \xi_{j}\right)-10\right] / 8
$$

where $\varepsilon$ reflects the status of crowding. $\lambda_{j}$ is the degree of membership between the candidate and template clouds. $\xi_{j}$ is the crowding coefficient for different grades of service. Then, the principle of equal spacing, which was widely used in the study of urban traffic performance $[4,5,9,15,21,22,27,43,44]$, was followed in this study to divide the $\varepsilon$ into $n$ grades. Finally, the GPC was calculated as follows:

$$
\mathrm{GPC}=\left\{\begin{array}{l}
\mathrm{I}, 0 \leq \varepsilon \leq 2.5 \\
\mathrm{II}, 2.5<\varepsilon \leq 5.0 \\
\mathrm{III}, 5.0<\varepsilon \leq 7.5 \\
\mathrm{IV}, 7.5<\varepsilon \leq 10
\end{array} .\right.
$$




\subsection{Model Results and Discussion}

After the cloud calculation and the normalization of the metrics for each facility, the digital features of the template cloud for the GPC and the normalization results were obtained, which are shown in Table 2.

Table 2. Results after normalization.

\begin{tabular}{|c|c|c|c|c|}
\hline Facility & Direction & Matrix & Original Value & Normalized Value \\
\hline \multirow{6}{*}{ Channel } & \multirow{3}{*}{ L1-L2 } & P1 & 2.290 & 1.000 \\
\hline & & $\mathrm{P} 2$ & 62.000 & 0.574 \\
\hline & & P3 & 25.630 & 1.000 \\
\hline & \multirow{3}{*}{ L2-L1 } & P1 & 109.440 & 1.000 \\
\hline & & $\mathrm{P} 2$ & 100.000 & 1.000 \\
\hline & & P3 & 0.000 & 1.000 \\
\hline \multirow{4}{*}{ Stairway } & \multirow{2}{*}{ upward } & P1 & 0.410 & 0.000 \\
\hline & & P3 & 45.600 & 0.318 \\
\hline & \multirow{2}{*}{ downward } & P1 & 11.130 & 1.000 \\
\hline & & P3 & 1.670 & 1.000 \\
\hline \multirow{2}{*}{\multicolumn{2}{|c|}{ Platform }} & $\mathrm{P} 1$ & 0.390 & 0.180 \\
\hline & & $\mathrm{P} 4$ & 0.360 & 0.000 \\
\hline
\end{tabular}

Note: when nobody exits at the facilities, the value of P1 is the effective utilization area value of facility, the value of $\mathrm{P} 2$ is 100.00 , and the value of P4 is 10.000 .

To develop the candidate cloud, the child cloud features and the forward normal cloud generator were used by Equation (9), and the three digital features of the candidate cloud for each facility was obtained by Equation (10). Then, the forward normal cloud generator algorithm was applied to calculate the degree of the membership for the four levels of GPC. Results are shown in Figure 8.

According to Figure 8, the degree of membership for each facility was as follows:

1. Channel: The measured degrees of the membership for the four grades were $0.3970,0.6030,0.0000$, and 0.0000 in the L1-L2 direction, which inclined to grade II. However, the measured degrees of the membership for the four grades were $0.8836,0.1164,0.0000$, and 0.0000 in the L2-L1 direction, which inclined to grade I.

2. Stairway: The measured degrees of the membership for the four grades were $0.0000,0.0001$, 0.6570 , and 0.3429 in the upward direction, which inclined to grade III. However, the measured degrees of the membership for the four grades were $0.8843,0.1157,0.0000$, and 0.0000 in the downward direction, which inclined to grade I.

3. Platform: The measured degrees of the membership for the four grades were $0.0000,0.0000$, 0.3594 , and 0.6406 , which inclined to grade IV.

Next, the GPC for each facility which was calculated by Equation (13), as shown in Table 3.

Table 3. The grade of pedestrian crowd (GPC) for the Candidate Cloud.

\begin{tabular}{ccccccccc}
\hline \multicolumn{2}{c}{ Facility } & Ex & En & He & $\varepsilon$ & GPC & $\begin{array}{c}\text { Status } \begin{array}{c}\text { Comfort } \\
\text { Description }\end{array} \\
\text { Perception }\end{array}$ \\
\hline \multirow{2}{*}{ Channel } & L1-L2 & 0.846 & 0.092 & 0.010 & 2.8 & II & $\begin{array}{c}\text { Relatively } \\
\text { unimpeded }\end{array}$ & Good \\
\cline { 2 - 9 } Stairway & L2-L1 & 0.996 & 0.093 & 0.010 & 1.5 & I & $\begin{array}{c}\text { Completely } \\
\text { unimpeded }\end{array}$ & Excellent \\
\cline { 2 - 9 } & downward & 0.143 & 0.070 & 0.010 & 7.1 & III & $\begin{array}{c}\text { Slightly } \\
\text { impeded }\end{array}$ & Ok \\
\hline \multirow{2}{*}{ Platform } & 0.996 & 0.111 & 0.010 & 1.6 & I & $\begin{array}{c}\text { Completely } \\
\text { unimpeded }\end{array}$ & Excellent \\
\hline
\end{tabular}



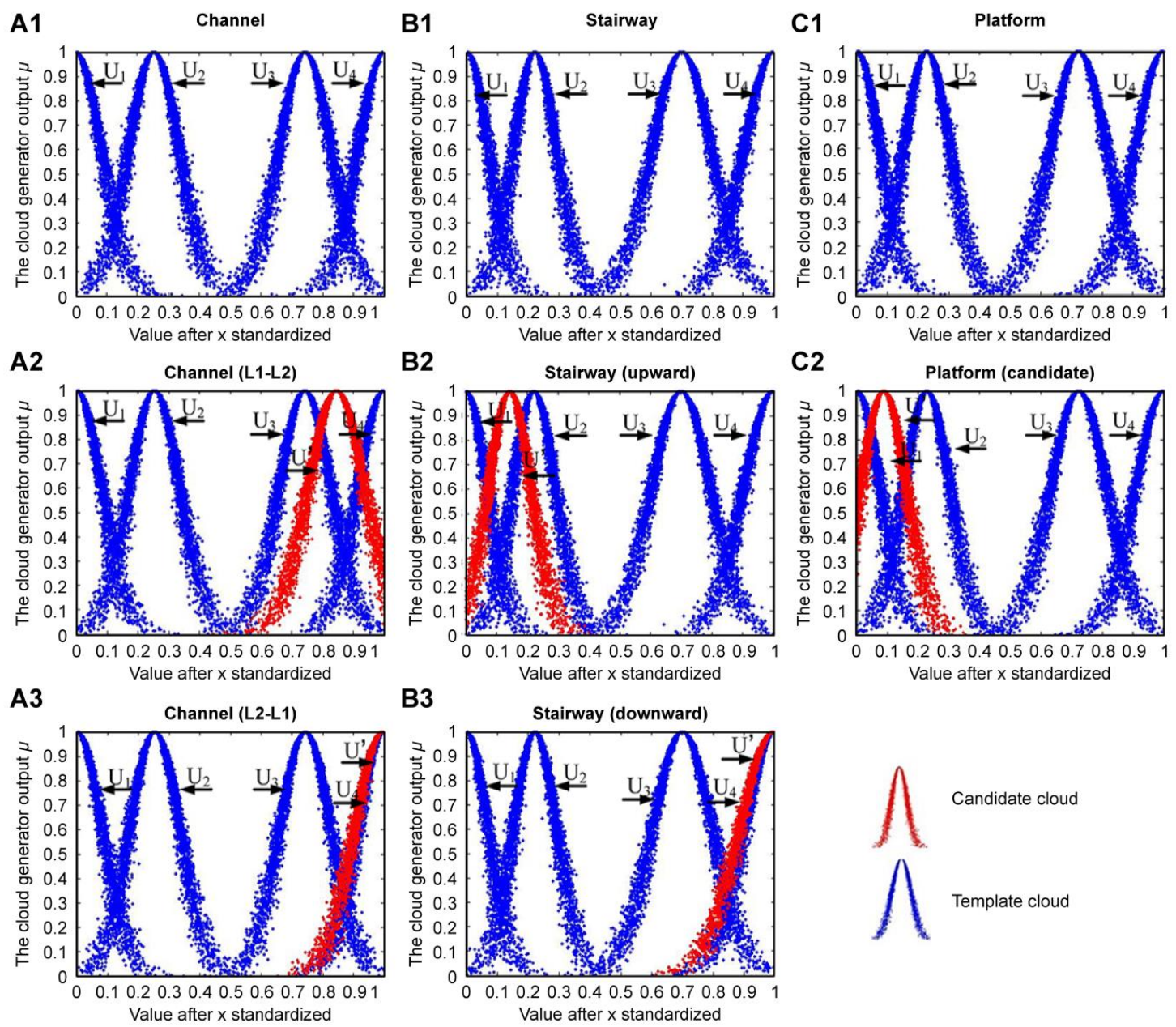

Figure 8. Comparison of the candidate cloud with the template cloud for each facility. (A1) The template cloud (channel). (B1) The template cloud (stairway). (C1) The template cloud (platform). (A2) the candidate cloud (channel (L1-L2)). (B2) the candidate cloud (stairway (upward)). (C2) the candidate cloud (platform). (A3) the candidate cloud (channel (L2-L1)). (B3) the candidate cloud (stairway (downward)).

Compared with the LOS assessment, the GPC assessment result was more accurate, as shown in Table 4.

Table 4. Assessment result between level of service (LOS) and GPC.

\begin{tabular}{|c|c|c|c|c|}
\hline & & Index & LOS & GPC \\
\hline \multirow{6}{*}{ Channel } & \multirow{3}{*}{ L1-L2 } & $P_{1}$ & B & \multirow{3}{*}{ II } \\
\hline & & $P_{2}$ & E & \\
\hline & & $P_{3}$ & B & \\
\hline & \multirow{3}{*}{ L2-L1 } & $P_{1}$ & A & \multirow{3}{*}{ I } \\
\hline & & $P_{2}$ & A & \\
\hline & & $P_{3}$ & A & \\
\hline \multirow{4}{*}{ Stairway } & \multirow{2}{*}{ Upward } & $P_{1}$ & E & \multirow{2}{*}{ III } \\
\hline & & $P_{3}$ & E & \\
\hline & \multirow{2}{*}{ Downward } & $P_{1}$ & A & \multirow{2}{*}{ I } \\
\hline & & $P_{3}$ & A & \\
\hline \multirow{2}{*}{\multicolumn{2}{|c|}{ Platform }} & $P_{1}$ & $\mathrm{D}$ & \multirow[b]{2}{*}{ IV } \\
\hline & & $P_{4}$ & E & \\
\hline
\end{tabular}


As a result, the GPC in channel L1-L2 was grade II in the GPC assessment process, while the passenger crowd degree was in levels B, E, and B by the corresponding P1, P2, and P3 in the LOS assessment. The GPC in the platform was grade IV using the GPC assessment process, while the passenger crowd degree was in levels D and E in the LOS assessment. Therefore, GPC was better and more realistic in illustrating the grade of crowd in metro stations.

For the channel facility in the L1-L2 direction, the GPC reached grade II in 13 time periods and remained in grade I in the rest of the time periods. For the channel facility in the L2-L1 direction, the GPC reached grade II in eight time periods. Besides that, the GPC reached grade III in four time periods, although the time length for each period was less than $30 \mathrm{~s}$. The reason for the inconsistent crowding status in the two directions was that the time difference of the two directions in Line 1 caused staggered arrival of the passengers (i.e., passenger flow was not concentrated), while the arrival time of the two directions in Line 2 was much more consistent, which made the passenger flow concentrated and intense. Although the passenger flow intensity during the study time was not very high, the passenger flow growth followed an irreversible trend with the continuous construction of the Ningbo rail transit network. Given the continuous increase in the passenger flow, the GPC might reach grade IV. In that situation, the passenger flow intensity in the L2-L1 direction of the channel facility could be reduced by adjusting the arrival time of Line 2 in both directions, thereby reducing potential security risks.

Overall, the current GPC for the facilities in the Gulou station was still considerable during the evening peak. Although the stairway facility did not show security risks due to no greater passenger flow in the study time, the safety hazards in the platform area were prominent and the safety hazards in the channel were more prominent as the passenger flow increased. Hence, some crowd safety management measures must be planned for accordingly beforehand.

\subsection{Crowd Management Measures}

According to previous literature review [38,39], four basic strategies for crowd management exist: increasing throughput, preventing blockades, distributing traffic, and limiting inflow. Additionally, this basic strategy framework is widely used in the categorization of crowd management measures. Hence, the crowd management measures in this study were proposed following the four basic strategies proposed by Hoogendoorn and Daamen [38,39] and NC model results.

The first category of strategies is to increase the throughput by identifying and possibly adapting the key bottlenecks in the infrastructure of metro station. The available measures are as follows: (a) separating bidirectional flows on path (or using safety barriers, isolation barriers to separate bidirectional flows); (b) creating funnel-shaped corridors; (c) creating two doors; (d) placing the object in front of bottleneck; (e) marking on the floor; (f) using handrail on stairs; (g) having fast and slow walking lanes; (h) having escalator directions; (i) changing the boarding and alighting procedures, and so on.

The second category of strategies is to prevent blockades, such as (a) using direction gates on platforms, (b) creating waiting locations (or buffer area at the bottleneck), and (c) relocating gates, kiosks, and machines. Measure (a) can be applied to force people to use a particular exit. Measure (b) can be employed by dedicating some waiting location in which interference between flows do not exist, to some extent, it will reduce walking space. Since it will involve the issue of interests, measure (c) may be complicated because the arrival of metro is crucial for using the revenues of the gates, kiosks, and machines.

The obtainable infrastructure should be fully and efficiently utilized. The third category of strategies is to guide the equilibrium distribution of traffic flow in facilities, such as (a) providing information about the stop position of trains; (b) increased attractiveness of route; (c) clear indication of less-used exits; (d) train stopping position adjustment, (e) walking time information provision, (f) manual intervention, and (g) separation of arrival tracks.

The fourth category of strategy is to limit the inflow so as to ensure that the number of pedestrians (passenger flow) remains below the critical density in the metro station. It can be done by deploying 
one-way brakes, temporally closing stations, or changing the schedule of metros. The gating control method can be employed temporarily and in urgent events with rush-hour demands. An example of the application of gating control approach to limit the inflow is modelled for a case in Beijing metro station, China [31]. However, the gating control measure will have some negative effects, such as reducing passenger comfort and increasing their travel time.

\section{Conclusions}

At present, the passenger crowd safety of the rail transit station is a big challenge for the development of the urban rail system. It is of great practice to assess the GPC of a metro station accurately and quickly so as to deal with rapid decision-making in emergency circumstances and enhance the ability of evacuation.

The present study applied the NC model to evaluate the GPC so as to solve the uncertainty and fuzziness nature of the passenger distribution in metro stations. Data were collected in the Ningbo Gulou rail transit station using a video sequence approach. The results showed the effectiveness of the four-grade grading criterion of the GPC and further confirmed the applicability of the NC model in the assessment of GPC. Although the four-grade grading criterion was a special case in this study, the proposed assessing method of the GPC can be used in a universal way to determine the crowding status in metro stations. Furthermore, this study provided several pedestrian safety measures for crowd management.

This study had some limitations. The survey was only conducted in the city of Ningbo, however, the operations of the urban rail transit system varied across cities. In some cities, such as Beijing, Shanghai, Guangzhou, and Hangzhou, urban rail transit networks have experienced rapid development and large-scale crowd events occur every day. The research method may not be suitable for these networks. To fill the gap, the neural networks approach is recommended in future studies, since neural networks currently provide the best solutions to many problems in automatic control, robot control, artificial intelligence, pattern recognition (i.e., image recognition, speech recognition), signal processing, and natural language processing. Furthermore, different weights for each facility characteristic of the NC model can be considered for further studies. This can help in determining more accurately whether the model is suitable as a standard of measure. Simultaneously, some innovative new measures can be developed.

Data Availability: The data used to support the findings of this study are included within the article.

Author Contributions: Conceptualization, J.Z.; Data curation, J.Z. and Y.W.; Investigation, S.G.; Methodology, J.Z. and S.G.; Resources, S.G. and J.Z.; Supervision, Y.W. and X.M.; Writing-review and editing, J.Z., Y.W., X.M. and M.Z.; Funding acquisition, J.Z. and X.M.

Funding: This study was supported by the Natural Science Foundation of Zhejiang Province (No. LQ19E080003), Philosophy and Social Science Foundation of Zhejiang Province (No. 18NDJC107YB), Educational Science Planning of Zhejiang Provincial Education Department (No. 2018SCG103), Natural Science Foundation of Ningbo Municipality (No. 2018A610127), Humanities and Social Science Research Program of Ministry of Education in China (No. 16XJCZH002) and the Fundamental Research Funds for the Central Universities (Grant Number 310823170657 and 300102238501$)$.

Conflicts of Interest: The authors declare that there are no conflicts of interest regarding the publication of this paper.

\section{References}

1. Xu, H.; Jiao, L.; Chen, S.; Deng, M.; Shen, N. An innovative approach to determining high-risk nodes in a complex urban rail transit station: A perspective of promoting urban sustainability. Sustainability 2018, 10, 2456. [CrossRef]

2. China Urban Rail Transit Association; Annual Report of China Urban Mass Transit; China Association of Metros: Beijing, China, 2019.

3. Zeng, L.; Liu, J.; Qin, Y.; Wang, L.; Yang, J. A passenger flow control method for subway network based on network controllability. Discret. Dyn. Nat. Soc. 2018, 2018, 1-12. [CrossRef] 
4. Yang, X.; Chen, A.; Ning, B.; Tang, T. Measuring route diversity for urban rail transit networks: A case study of the Beijing metro network. IEEE Trans. Intell. Transp. Syst. 2017, 8, 259-268. [CrossRef]

5. Huang, J.; Zhou, F.; Xi, M. Calculation method for load capacity of urban rail transit station considering cascading failure. J. Adv. Transport. 2018, 2018, 1-12. [CrossRef]

6. Guo, Y.; Li, Z.; Liu, P.; Wu, Y. Modeling correlation and heterogeneity in crash rates by collision types using full Bayesian random parameters multivariate Tobit model. Accid. Anal. Prev. 2019, 128, 164-174. [CrossRef] [PubMed]

7. Guo, Y.; Essa, M.; Sayed, T.; Haque, M.; Washington, S. A comparison between simulated and field-measured conflicts for safety assessment of signalized intersections in Australia. Transp. Res. Part C Emerg. Technol. 2019, 101, 96-110. [CrossRef]

8. Kyriakidis, M.; Hirsch, R. and Majumdar, A. Metro railway safety: An analysis of accident precursors. Saf. Sci. 2012, 50, 1535-1548. [CrossRef]

9. Shen, W.; Xiao, W.; Wang, X. Passenger satisfaction evaluation model for Urban rail transit: A structural equation modeling based on partial least squares. Transp. Policy 2016, 46, 20-31. [CrossRef]

10. Guo, Y.; Li, Z.; Wu, Y.; Xu, C. Evaluating factors affecting electric bike users' registration of license plate in China using Bayesian approach. Transp. Res. Part F Traffic Psychol. Behav. 2018, 59, 212-221. [CrossRef]

11. Ma, C.; Hao, W.; Wang, A.; Zhao, H. Developing a coordinated signal control system for urban ring road under the vehicle-infrastructure connected environment. IEEE Access 2018, 6, 52471-52478. [CrossRef]

12. Chen, F.; Chen, S.; Ma, X. Analysis of hourly crash likelihood using unbalanced panel data mixed logit model and real-time driving environmental big data. J. Saf. Res. 2018, 65, 153-159. [CrossRef] [PubMed]

13. Ma, X.; Chen, S.; Chen, F. Multivariate space-time modeling of crash frequencies by injury severity levels. Anal. Methods Accid. Res. 2017, 15, 29-40. [CrossRef]

14. Niu, H.; Zhou, X. Optimizing urban rail timetable under time-dependent demand and oversaturated conditions. Transp. Res. Part C Emerg. Technol. 2013, 36, 212-230. [CrossRef]

15. Ma, C.; Yang, D.; Zhou, J.; Feng, Z.; Yuan, Q. Risk riding behaviors of urban e-bikes: A literature review. Int. J. Environ. Res. Public Health. 2019, 16, 2308. [CrossRef] [PubMed]

16. Chen, F.; Chen, S. Injury severities of truck drivers in single-and multi-vehicle accidents on rural highways. Accid. Anal. Prev. 2011, 43, 1677-1688. [CrossRef] [PubMed]

17. Mahudin, N.D.M.; Cox, T.; Griffiths, A. Measuring rail passenger crowding: Scale development and psychometric properties. Transp. Res. Part F Traffic Psychol. Behav. 2012, 15, 38-51. [CrossRef]

18. Haywood, L.; Koning, M.; Monchambert, G. Crowding in public transport: Who cares and why? Transp. Res. Part A Policy Pract. 2017, 100, 215-227. [CrossRef]

19. Kang, L.; Meng, Q. Two-phase decomposition method for the last train departure time choice in subway networks. Transp. Res. B Meth. 2017, 104, 568-582. [CrossRef]

20. He, L.; Liang, Q.; Fang, S. Challenges and innovative solutions in urban rail transit network operations and management: China's Guangzhou metro experience. Urban Rail Transit. 2016, 2, 33-45. [CrossRef]

21. Zhou, J.; Chen, H.; Yang, J.; Yan, J. Pedestrian evacuation time model for urban metro hubs based on multiple video sequences data. Math. Probl. Eng. 2014, 2014, 1-11. [CrossRef]

22. Jiang, S.; Sun, Y.; Du, Y. The influence of congestion on the choice of public transport mode. J. Tung-chi Univ. Nat. Sci. 2012, 40, 1831-1835.

23. Basu, D.; Hunt, J. Valuing of attributes influencing the attractiveness of suburban train service in Mumbai city: A stated preference approach. Transp. Res. Part A Policy Pract. 2012, 46, 1465-1476. [CrossRef]

24. Tirachini, A.; Hensher, D.A.; Rose, J. Crowding in public transport systems: Effects on users, operation and implications for the estimation of demand. Transp. Res. Part. A Policy Pract. 2013, 53, 36-52. [CrossRef]

25. Yang, J.; Hou, Z. A grey Markov based on large passenger flow real-time prediction model. J. Beijing Jiaotong Univ. 2013, 2, 23-30.

26. Lam, W.H.; Cheung, C.Y.; Lam, C. A study of crowding effects at the Hong Kong light rail transit stations. Transp. Res. Part A Policy Pract. 1999, 33, 401-415. [CrossRef]

27. Cao, S.; Yuan, Z.; Zhang, C.; Li, Z. LOS classification for urban rail transit passages based on passenger perceptions. J. Transp. Syst. Eng. Inf. Tech. 2009, 9, 99-104. [CrossRef]

28. Chen, P.; Zeng, W.; Yu, G. Assessing right-turning vehicle-pedestrian conflicts at intersections using an integrated microscopic simulation model. Accid. Anal. Prev. 2019, 129, 211-224. [CrossRef] [PubMed] 
29. Grisé, E.; El-Geneidy, A. Where is the happy transit rider? evaluating satisfaction with regional rail service using a spatial segmentation approach. Transp. Res. Part A Policy Pract. 2018, 114, 84-96. [CrossRef]

30. Birago, D.; Mensah, S.O.; Sharma, S. Level of service delivery of public transport and mode choice in Accra, Ghana. Transp. Res. Part F Traffic Psychol. Behav. 2017, 46, 284-300. [CrossRef]

31. Pel, A.J.; Bel, N.H.; Pieters, M. Including passengers' response to crowding in the Dutch national train passenger assignment model. Transp. Res. Part A Policy Pract. 2014, 66, 111-126. [CrossRef]

32. Tirachini, A.; Sun, L.; Erath, A.; Chakirov, A. Valuation of sitting and standing in metro trains using revealed preferences. Transp. Policy 2016, 47, 94-104. [CrossRef]

33. TRB. Transit Capacity and Quality of Service Manual, 2nd ed.; Transportation Research Board: Washington, DC, USA, 2003.

34. Li, Z.; Hensher, D. Crowding in public transport: A review of objective and subjective measures. J. Public Trans. 2013, 16, 1-28. [CrossRef]

35. Jiang, C.S.; Deng, Y.F.; Hu, C.; Chow, W. Crowding in platform staircases of a subway station in China during rush hours. Saf. Sci. 2009, 47, 931-938. [CrossRef]

36. Zhang, Q.; Han, B.; Li, D. Modeling and simulation of passenger alighting and boarding movement in Beijing metro stations. Transp. Res. Part C Emerg. Technol. 2008, 16, 635-649. [CrossRef]

37. Guo, Y.; Zhou, J.; Wu, Y.; Li, Z. Identifying the factors affecting bike-sharing usage and degree of satisfaction in Ningbo, China. PLoS ONE 2017, 12, e0185100. [CrossRef] [PubMed]

38. Hoogendoorn, S.P.; Daamen, W. Pedestrian behavior at bottlenecks. Transp. Sci. 2005, 39, 147-159. [CrossRef]

39. Daamen, W.; Hoogendoorn, S. Experimental research of pedestrian walking behavior. Transp. Res. Rec. J. Transp. Res. B 2003, 2003, 20-30. [CrossRef]

40. Li, D.; Liu, C.; Gan, W. A new cognitive model: Cloud model. Int. J. Intell. Syst. 2009, 24, 357-375. [CrossRef]

41. Zhou, J.; Mao, X.; Wang, Y.; Zhang, M.; Dong, S. Risk assessment in urban large-scale public spaces using dempster-shafer theory: An empirical study in Ningbo, China. Int. J. Environ. Res. Public Health 2019, 16, 2942. [CrossRef]

42. Dai, C.; Zhu, Y.; Chen, W.; Lin, J. Cloud model based genetic algorithm and its applications. Acta Electron. Sinica 2007, 35, 1419.

43. Zuo, Z.; Yin, W.; Yang, G.; Zhang, Y.; Yin, J.; Ge, H. Determination of bus crowding coefficient based on passenger flow forecasting. J. Adv. Transp. 2019, 2019, 1-12. [CrossRef]

44. Klanjšček, J.; Geček, S.; Marn, N.; Legović, T.; Klanjšček, T. Predicting perceived level of disturbance of visitors due to crowding in protected areas. PLoS ONE 2018, 13, e0197932. [CrossRef] [PubMed] 